\title{
EL DELITO DE INFORMACIÓN PRIVILEGIADA EN EL MERCADO DE CAPITALES (ART. 307 CPA).
}

\author{
THE CRIME OF INSIDER TRADING IN THE CAPITAL \\ MARKET ACCORDING TO ART. 307 OF THE ARGENTINEAN \\ CRIMINAL CODE
}

SEBASTIAN ALBERTO DONNA*

\section{Resumen}

Este trabajo aborda el delito de información privilegiada o insider trading en el mercado de capitales según el artículo 307 del Código penal argentino.

\section{Palabras Clave}

Derecho penal; lavado de dinero; información privilegiada; insider trading; mercado de capitales

\begin{abstract}
This paper deals with the crime of insider trading in the capital market according to art. 307 of the Argentinean Criminal Code.
\end{abstract}

\footnotetext{
Artículo recibido para su evaluación el 23 de noviembre de 2021, y aprobado para su publicación el 15 de diciembre de 2021.

*Doctor en Derecho penal, UBA; Abogado, UBA; Magister Derecho \& Economía, UBA

+ Magister en Economía Aplicada, UTDT; antiguo Gastwissenschaftler Georg-August Universität Göttingen. Institut für Kriminalwissenschaften. CEDPAL (Alemania); Docente, UBA. Email:
} 


\section{Keywords}

Criminal law; money laundering; insider trading; insider information; capital market.

\section{INTRODUCCIÓN.}

Este trabajo aborda el delito de información privilegiada o insider trading en el mercado de capitales según el art. 307 del Código penal argentino.

La necesidad de regular el uso de información privilegiada ha sido durante mucho tiempo una cuestión controvertida. El crítico más conocido de la prohibición de las operaciones con información privilegiada es el estadounidense Henry G. Manne, que publicó un estudio económico sobre las operaciones con información privilegiada en 1966 y llegó a la conclusión de que éstas son beneficiosas para la eficacia de la asignación del mercado de capitales, ya que la información privilegiada fluye gradualmente hacia la bolsa o el precio del mercado y contribuye así a la formación de precios justos. Sin embargo, sigue sin estar claro si se puede medir con precisión la influencia de la información privilegiada en la formación de los precios y cómo hacerlo. ${ }^{1}$

$1 \quad$ POELZIG, Dörte: Kapitalmarktrecht. C.H. Beck, 2018. p.173, Rn 364, München 2018. La famosa frase que dice los movimientos del mercado lo descuentan todo, probablemente sea la piedra angular del análisis técnico. El técnico cree que cualquier cosa que posiblemente pueda afectar el precio -por razones fundamentales, políticas, psicológicas u otras- se refleja realmente en el precio de ese mercado. Se concluye, entonces, que todo lo que hace falta es un estudio de los movimientos de los precios. Lo que significa simplemente es que toda la información relevante sobre las ganancias, nuevos productos, gestión, y demás informaciones (los datos fundamentales) actualmente conocidas ya están incorporadas en el precio de sus acciones. WEINSTEIN, Stan: Secretos para ganar en los mercados alcistas y bajistas. Alor editions, Barcelona, 2014, pp. 17/8. La idea de que los precios se mueven por tendencias, de esta manera, el único propósito de la representación grafica de los movimientos de precios de un mercado es identificar tendencias que están en las primeras etapas de su desarrollo, con el fin de que las transacciones vayan en la dirección de dichas tendencias. Hay una diferencia entre el pronostico técnico y la previsión fundamental. Mientras que el análisis técnico se concentra en el estudio de los movimientos del mercado, el análisis fundamental lo hace en las fuerzas económicas de la oferta y la demanda que hacen que los precios suban, bajen o se queden igual. El enfoque fundamental examina todos los factores relevantes que afectan al precio de un mercado para determinar el valor intrínseco de dicho mercado. El valor intrínseco es lo que los fundamentos indican como valor real de algo según la Ley de la oferta y la demanda. Si este valor intrínseco esta 
En cuanto a la utilidad de la información privilegiada, también se argumenta que ésta podría crear incentivos para que los directivos actúen con ánimo de lucro. Dado que, debido a la separación de la propiedad y la gestión, los beneficios de la actividad empresarial benefician principalmente a los accionistas y no a la gestión (conflicto principal-agente), esto podría compensarse permitiendo el uso de información privilegiada. Sin embargo, la remuneración de la información privilegiada se basaría en el acceso a la información relevante y no en la gestión empresarial, de modo que los gestores de las empresas podrían beneficiarse no sólo de la información positiva sino también de la negativa, algo que se haría a través de la venta en corto y las opciones de venta.

Por lo tanto, para Dörte Poelzig, permitir el uso de información privilegiada no solo frustraría el objetivo de promover la gestión en interés de la empresa, sino que prácticamente lo convertiría en su contrario. Por último, el principal argumento en contra de la prohibición de las operaciones con información privilegiada es que éstas no conocen víctimas (delito sin víctimas), ya que la pérdida de un inversor que negocia con una persona con información privilegiada es tan elevada como cuando negocia con un "extraño". Sin embargo, la totalidad de los inversores que negocian sin conocer la información privilegiada sufren una pérdida neta igual a la ganancia del iniciado. Por lo tanto, no se trata de un delito sin víctimas en sentido estricto, como la posesión de drogas. En consecuencia, se reconoce en gran medida la necesidad de prohibir el uso de información privilegiada. La prohibición de las operaciones con información privilegiada tiene por objeto garantizar la igualdad de oportunidades para todos los inversores en el mercado de capitales y aumentar la confianza de los inversores en la

por debajo del precio actual de mercado, quiere decir que el mercado esta sobrevaluado y debe venderse. Si el precio de mercado esta por debajo del valor intrínseco, entonces el mercado esta infravalorado y debe comprarse. Ambos enfoques del pronostico sobre el mercado intentan solucionar el mismo problema, es decir, determinar la dirección en la que los precios probablemente se moverán, pero considerando este problema desde diferentes posiciones. Las discrepancias aparecen en que unos sostienen, que el precio del mercado tiende a marcar el camino de los fundamentos conocidos. En otras palabras, el precio del mercado actúa como un indicador clave de los fundamentos o del conocimiento convencional del momento. Mientras que los fundamentos conocidos ya han sido descontados y ya están reflejados en el mercado, los precios reaccionan ahora a los fundamentos desconocidos. MURPHY, John, Análisis técnico de los mercados financieros. Planeta, Barcelona 2018. p.29. 
integridad del mercado y, por tanto, su disposición a invertir, lo que a su vez refuerza el funcionamiento del mercado de capitales. ${ }^{2}$

Por ello la prohibición de la información privilegiada se dirigiría a fortalecer la confianza del inversor en el trato igualitario de todos los operadores del mercado en su acceso a la información relevante, y de ese modo al mismo tiempo fortalecer también el correcto funcionamiento de los mercados.

El tema del mercado de valores, como es sabido, no es un tema azaroso (por supuesto que tiene una parte que puede ser de suerte) donde las personas van a realizar una compra-venta de acciones o bonos, si no que, tiene un análisis técnico (sistema Fibonacci, Dow, gráficos, precios, volumen, interés abierto, medias móviles, etc.).

Esto da como resultado las tareas esenciales de la ley del mercado de capitales, el público inversor debe tener acceso a tanta información como sea posible, relevante para el valor de un instrumento financiero, de modo que los inversores no corran el riesgo de adquirir un instrumento financiero inadecuado o sobrevalorado y luego retirar su capital del mercado de manera decepcionante. Se tiene en cuenta en un gran número de obligaciones de información en virtud de la legislación del mercado de capitales, que obliga a los emisores en particular, pero también a otros agentes del mercado de capitales, a poner a disposición del mercado la información pertinente en determinadas situaciones. ${ }^{3}$

Ahora bien, el problema aparece que la información privilegiada distorsiona el análisis basado en la información que da el mercado, información que es publica e igual para todos. La información privilegiada rompe esa igualdad, rompe la igualdad que da el libre mercado de la ofertademanda, lo que llevaría a que todo el trabajo del análisis realizado sobre precios e información pierda sentido, y lo que podría haber implicado una ganancia termina siendo una perdida.

\section{EI INSIDER TRADING.}

La referencia al insider trading es muy frecuente en la doctrina para referirse al uso indebido de información privilegiada o reservada en el ámbito del mercado de valores. Alude en su denominación a personas con

$2 \quad$ POELZIG, op. cit., p.173, $\mathrm{n}^{\circ} 364$

3 POELZIG, op. cit., p. 1, nº. 2 . 
posibilidad de acceso a esa información, y a la negociación por la cual típicamente se la aprovecha. ${ }^{4}$

La figura del insider, evoca el carácter de una persona vinculada con un emisor (en sentido amplio) de valores negociables en el mercado de valores, que por esa relación puede obtener un beneficio económico, o evitar un perjuicio al tener acceso a información no pública. ${ }^{5}$

La doctrina absolutamente mayoritaria atribuye el origen de la regulación legal del insider trading a la normativa norteamericana sobre títulos valor, esto es, la Securities Act (1933) y la Securities Exchange Act (1934), surgidas a raíz del famoso crack bursátil de la bolsa de Nueva York en $1929 .^{6}$

El primer caso de insider trading es el conocido Cady, Robert \& Co (1961). Se trata del primer caso de uso de información privilegiada con el que se inició lo que se conoce como nueva era del Derecho de insider trading. En este supuesto, el socio de una casa de bolsa fue informado por el consejo de una compañía que el consejo de administración había acordado reducir los dividendos. Inmediatamente antes de que la información se hiciere pública, el sujeto procedió a vender las acciones de esa compañía.

En el caso SEC v. Texas Gulf Sulphur Co. (1968) el Tribunal Federal aplico la regla "informar o abstenerse" (disclose or abstain rule), en virtud de la cual se obliga a quien poseen información relevante para las cotizaciones a comunicar antes de llevar a cabo cualquier operación. Aquí los directivos y empleados compraron acciones de una compañía minera para la que trabajaban, antes que se hiciera público el descubrimiento de importantes reservas mineras. ${ }^{7}$

Otro caso importante es el de Shapiro v. Merrill Lynch Pierce Fenner \&Smith (1974), la importancia de esta caso radica en que se condenó a la sociedad propiamente dicha y no a los inversores, pues entre estos y la otra compañía involucrada no existía ninguna relación de confianza. Así, Merrill Lynch recibió información confidencial por parte de los administradores de la sociedad. Douglas Lynch Pierce comunico dicha información a los

4 PAOLANTONIO, Martin E.: Derecho penal y mercado financiero: ley 26.733. Edit. Abeledo-Perrot. Bs.As. 2012, p. 63

5 Ibídem

6 VEGA GUTIÉRREZ, José Zamyr: Mercado de Valores en Derecho penal. Abuso de información privilegiada bursátil: Insider Trading. BdeF. Madrid. 2013. pp. 9-10

7 VEGA GUTIÉRREZ, op. cit., p. 11. 
clientes institucionales, que rápidamente se deshicieron de las acciones de Douglas, provocando así el desplome de las acciones. ${ }^{8}$

En el caso U.S v. O'Hagan (1988) se condenó el 25 de junio de 1997 a un abogado que gano 4.3 millones de dólares mediante la compra de opciones sobre acciones de una compañía que iba a ser adquirida a través de una OPA por otra que era cliente de la firma para la que trabajaba el abogado. De esta forma, se asimila al insider a quien se apodera de información confidencial para negociar títulos en los mercados de valores, quebrantando la lealtad debida a la fuente de información. Este caso marco un giro sustancial en la jurisprudencia, ya que por primera vez el Tribunal Supremo de los Estados Unidos estableció que la lealtad quebrantada no ha de ser necesariamente la debida a la compañía emisora de los títulos. ${ }^{9}$

El mercado de valores español ha sido también escenario de algunos casos emblemáticos de aparentes operaciones con información privilegiada; sin embargo no se encuentran muchas condenas por información privilegiada. El caso Villalonga (1998) el TS emitió una sentencia en la que afirma la existencia de insider trading, pero que la acción penal había prescripto y, en consecuencia exime de responsabilidad penal a los imputados. El 2 de enero de 1998 Juan Villalonga adquirió 264.224 opciones sobre acciones de Telefónica con un crédito de 200 millones de pesetas, obtenido de Argentina. En ese momento, Villalonga era presidente de Telefónica y en esos días negociaba en secreto una fusión con la compañía telefónica estadounidense MCI-WorldCom. El consejero de Telefónica, Alberto Cortina Alcocer, también realizó simultáneamente una operación similar por la misma cuantía, aunque a través de una sociedad controlada por el. Villalonga obtuvo ganancias por el orden de los 21.300 .000 pesetas en tan solo 14 días, ya que decidió vender sus títulos antes del vencimiento de los mismos, después de que el presidente de la CNMV Juan Fernández Armesto le recomendara que diera a conocer públicamente su compra, a pesar de no estar legalmente obligado a ello. La CNMV realizó una investigación sobre la operación pero tuvo que cerrarla ya que no pudo probar que se habían valido de información privilegiada. ${ }^{10}$

Otro caso importante lo encontramos en la jurisprudencia chilena en el caso LAN (Superintendencia de Valores y seguros c/Cueto Plaza, Juan) donde se determino que los estados financieros de LAN, aprobados al 30

\footnotetext{
$8 \quad$ Ibídem

9 VEGA GUTIÉRREZ, op. cit., p. 13

10 Ibídem
} 
de junio de 2006 en la sesión de directorio de esa Sociedad el 24 de julio de ese año, como los de cualquier otro ente societario, regido por la LMV, contienen y representan información privilegiada, en tanto no había sido divulgada al mercado y poseía, de suyo, la suficiente fuerza para influir en la cotización de los valores emitidos independientemente de que este resultado se produzca o no. Señala que es un hecho de la causa que la información, capaz de influir en tan relevantes términos, sólo vino a ser efectivamente conocida por el mercado recién en la mañana del miércoles 26 de julio de 2006, haciendo- la suya el reclamante el mismo día 24 de ese mes, al término de la sesión de directorio de LAN, con el mérito de sus propias declaraciones cuando admite haber adquirido para Cantábrico las 250.000 acciones de LAN por sugerencia de Sebastián Piñera Echeñique. ${ }^{11}$

\section{LA INFORMACIÓN PRIVILEGIADA.}

Ahora bien, el artículo 307 del CPA reprime el llamado abuso de información privilegiada. De acuerdo a la definición de la expresión "información privilegiada" recogida por el artículo. 77 del CP, ella comprende toda información no disponible para el público cuya divulgación podría tener significativa influencia en el mercado de valores.

$\mathrm{Al}$ respecto el artículo 2 del decreto 677/01 perteneciente al Régimen de Transferencia de la Oferta Publica dice "Información reservada o privilegiada: A toda información concreta que se refiera a uno o varios valores, o a uno o varios emisores de valores, que no se haya hecho pública y que, de hacerse o haberse hecho pública, podría influir o hubiera influido de manera sustancial sobe las condiciones o precio de colocación o el curso de negociación de tales valores". ${ }^{12}$

En Chile, el abuso de información privilegiada se encuentra sancionado, administrativa y penalmente tanto en la Ley de Mercado de Valores $\mathrm{N}^{\circ} 18.045$ de 1981 (artículo 165, 60 e), g) y h) como en el Decreto Ley 3.500 de 1980 sobre Sistema de Pensiones (artículo 159). Con el concepto de abuso de información privilegiada se designan una serie de conductas desvaloradas administrativa y penalmente y que abarcan todo aprovechamiento de cierta información no pública ya sea por medio de

11 VÁSQUEZ PALMA, María Fernanda: "Caso LAN y uso de información privilegiada: un análisis de la correcta delimitación de las infracciones legales". En: Revista Ius Praxis, Año 16 n $^{\circ}$ 2, 2010. pp 416-484.

12 http://servicios.infoleg.gob.ar/infolegInternet/anexos/65000-69999/67128/norma.htm 
su utilización en transacciones en el mercado de valores o a través de la divulgación o difusión de la misma. ${ }^{13}$

En España, el concepto de información privilegiada se encuentra definida en el artículo 7 RAM. Por tal se entiende toda información que reúne las siguientes características a) que sea concreta; b) que no se haya hecho político (reservada); c) que se refiera a un instrumento financiero, por lo menos, o a sus derivados; d) que, en el supuesto de ser publicada, sea capaz de influir de forma apreciable en los precios de cotización de los instrumentos a los que la información se refiere.

En Alemania, la prohibición de las operaciones con información privilegiada regulada originalmente en el $\S 14$ de la WpHG (Gesetz über den Wertpapierhandel - Wertpapierhandelsgesetz) para aplicar la MAD (Market Abuse Directive -Richtlinie 2003/6/EG des Europäischen parlament und des Rates v. 28.1.2003 über Insider-Geschäfte und Marktmanipulation) se encuentra ahora en el §14 de MAR (Marktmissbrauchsrecht). Información desconocida y relevante para la negociación de valores. ${ }^{14}$

De esta manera, se trata de información precisa que no se conoce públicamente, que se refiere directa o indirectamente a uno o varios emisores de instrumentos financieros o a uno o varios instrumentos financieros y que, si se conociera públicamente, podría tener un efecto significativo en el precio de estos instrumentos financieros o en el precio de los instrumentos financieros derivados relacionados. ${ }^{15}$

La esencia de la información privilegiada es que no es todavía de dominio público. Según el $\S 13$ de la WpHG alemana (versión antigua), la información sobre una circunstancia o un acontecimiento se consideraba de dominio público si un número indeterminado de personas podía tomar nota de ella. Para ello, bastaba con el llamado público sectorial, al que

13 GARCIA PALOMINOS, Gonzalo: "Modelo de protección en normas administrativas y penales que regulan el abuso de Información Privilegiada en la legislación chilena". En: Política crim., Vol. 8, No 15 (Julio 2013), Art. 2, pp. 23 - 63. Chile. [http://www. politicacriminal.cl/Vol_08/n_15/Vol8N15A2.pdf]

14 POELZIG, op. cit., p. 172.

Con la Directiva de abuso de mercado 2014/57/UE (MAD), el legislador europeo impuso una transformación integral de la ley de abuso de mercado a los Estados miembros de la UE en 2014. Esto también incluye la obligación de establecer sanciones penales por operaciones con información privilegiada y manipulación del mercado, al menos en casos graves y en caso de intención. La incitación y la ayuda, así como el intento de abusar del mercado, también deben ser sancionados penalmente en todos los países de la UE en el futuro.

15 POELZIG, op. cit., p. 173. 
pertenecen todos los profesionales del mercado. En el caso de la publicidad sectorial, se consideró que la información era de dominio público, independientemente de que los inversores privados también pudieran tomar nota de la información. En cambio, con la nueva ley, lo importante es el amplio público inversor. No se trata del público en general, sino de un público del mercado de capitales que, sin embargo, va más allá del círculo de participantes profesionales en el mercado e incluye a todos los inversores en el mercado de capitales. ${ }^{16}$

En cualquier caso, el público inversor puede tomar nota si la información se difunde por la prensa nacional $\mathrm{u}$ otros medios de comunicación (como la televisión o Internet). Sin embargo, por regla general, el público inversor en general también es informado mediante anuncios ad hoc por parte de los emisores de conformidad con el $\S 17$ MAR, en la medida en que estos anuncios son transmitidos electrónicamente a sus clientes por agencias especializadas en la difusión de noticias empresariales (por ejemplo, Reuters) (§17, párrafo 10 MAR en relación con el §2 de la OED 2016/1055). La información privilegiada debe divulgarse de forma gratuita, simultánea y lo más rápidamente posible a "todas las categorías de inversores de la Unión" (considerando 1, frase 2 del Reglamento 2016/1055). ${ }^{17}$

Es sabido que el público en general no está presente cuando se divulga información en una junta general, ya que solo pueden asistir los accionistas y no los posibles inversores. Además, a las ruedas de prensa solo asiste un grupo limitado de personas. La información falsa no es información privilegiada, de acuerdo con el §17 (2) MAR, la información debe considerarse precisa si se refiere a circunstancias o un evento que "ya existió" o "ha ocurrido". En el caso de información incorrecta, este no es precisamente el caso. Incluso en el uso cotidiano del lenguaje, la "información incorrecta" no es información, sino desinformación que no conduce al conocimiento sino a un error. Si la persona con información privilegiada cree que la información es verdadera, puede, sin embargo, ser procesado por intento de uso de información privilegiada (considerando 119 (4) WpHG). ${ }^{18}$

A modo de síntesis, podemos decir que, la información es privilegiada cuando su divulgación haría variar la cotización de los valores a los que la información se refiere. Tres notas destacan en el concepto de información

\footnotetext{
16 POELZIG, op. cit., . 183/4.

17 Ibídem.

18 POELZIG, op. cit., p. 176.
} 
privilegiada. En primer lugar, se debe tratar de una información reservada que no ha sido hecha pública. En segundo lugar, debe ser una información concreta. Simples rumores, de que algo puede suceder, no constituyen información privilegiada. Y en tercer lugar debe tener la relevancia de ser capaz de influir sobre la cotización del instrumento al que se refiere. La información sobre una opa en curso reúne estos tres elementos, pues es reservada, afecta a unos valores concretos y de hacerse pública haría variar la cotización. ${ }^{19}$

\section{ELARTÍCULO 307 DEL CÓDIGO PENAL ARGENTINO DESDE LA TEORÍA DEL DELITO.}

\section{Bien jurídico.}

En la discusión sobre el bien jurídico se ha sostenido que, con la sanción del abuso de información privilegiada se ha buscado garantizar la igualdad de condiciones y oportunidades de todos los inversores, es decir, tanto los que se encuentran dentro del mercado de capitales y poseen ese tipo de información y los que se encuentran fuera y no la tienen. ${ }^{20}$

Así las cosas, es el correcto desenvolvimiento del orden económico y financiero del país. El suministro o el uso de esa información privilegiada por parte de las personas enumeradas en esta norma provocan una alteración en los mercados financieros y bursátiles, lo que conduce a la afectación de la confianza de los inversores. ${ }^{21}$ Existe un bien jurídico que consiste en la seguridad de las transacciones y la inconmovilidad del mercado de valores. ${ }^{22}$

Señala Luigi Foffani que, se conforma un bien jurídico supranacional (el ahorro) que se separa de la esfera del patrimonio individual y que se convierte en inversión, que en los casos normales se confía a los institutos de crédito y otros intermediarios financieros. ${ }^{23}$

19 ZUNZUNEGUI, Fernando: ¿Qué es el insider trading? En: Revista de Derecho del Mercado Financiero. rdmf.wordpress.com. Octubre de 2006, p. 1

20 DONNA, Edgardo: Derecho penal. Parte especial. Tomo IV. 3 edición actualizada. Rubinzal-Culzoni. Santa Fe, 2014. p. 532

21 ABOSO, Gustavo Eduardo: Código Penal. Comentado, concordado con jurisprudencia, 4 edición, BdeF, 2017, p. 1515

22 Donna, op. cit., p. 533

23 FOFFANI, Luigi: Delitos bancarios y bursátiles. p.113. En: Eurodelitos. El Derecho penal económico en la Unión Europea. director, Klaus Tiedemann, Coordinador. Adán Nieto Martin. Ediciones Universidad de Castilla-La Mancha, 2004 
En relación a ello surgen distintas necesidades de protección que se caracterizan en función de dos términos clave: protección de funciones y protección del inversor. Por un lado, se trata de la protección del inversor frente a los intermediarios financieros o frente a otros participantes del mercado. En este caso hay que distinguir entre la protección al inversor particular aisladamente considerado (protección individual) y la protección de la figura del inversor en el sentido de la masa de inversores (protección de carácter supraindinvidual). Por el otro lado, se tarta de la tutela de las condiciones de funcionamiento de los mercados de capitales. ${ }^{24}$

En muchos casos, la información sobre futuras inversiones o fusiones de sociedades cuyos títulos cotizan en bolsa desemboca en su empleo indebido por parte de los operadores bursátiles lo que provoca un alza injustificada de las acciones bursátiles. ${ }^{25}$

En la doctrina económica y jurídica (mercantil, administrativa y penal) comúnmente se afirma que las operaciones con información privilegiadas en el mercado de valores pueden afectar una pluralidad de intereses jurídicos. En este sentido la doctrina española suele invocar el planteamiento de Stratenwerth, quien agrupa en alrededor de tres criterios las afectaciones que provoca el uso de información privilegiada. ${ }^{26}$

Así en primer lugar, se sostiene que las operaciones de iniciación pueden configurarse como un abuso de confianza frente a la empresa en la que el insider labora o para la que desempeña su actividad profesional, en segundo lugar, tales abusos constituyen un engaño a otros inversores $y$, en ese sentido, una violación del principio de igualdad de oportunidad, y en tercer lugar, dichas operaciones pueden perjudicar intereses económicos generales, al vulnerar la confianza del inversor en el correcto y transparente funcionamiento del mercado de capitales. ${ }^{27}$

\section{Acciones típicas.}

Las acciones típicas son dos: suministrar o utilizar información privilegiada a la que el autor tuvo acceso en ocasión de su actividad. Para Orce, para criminalizarlas, lo primero sería constatar que la conducta prohibida realmente ocasione un perjuicio al mercado. Esa parece ser la

$24 \quad$ FOFFANI, op. cit., p. 113/4

25 ABOSO, op. cit., p. 1515.

26 VEGA GUTIÉRREZ, op. cit., p. 103

27 Ibídem 
orientación de este tipo penal, sobre todo si se tiene en cuenta que el inc. c) del artículo 308 agrava la pena cuando el uso de la información privilegiada "causare un grave perjuicio en el mercado de valores". ${ }^{28}$

De esta manera, la acción típica puede revestir distintas formas: de adquisición o venta directa o indirecta (a través de una persona intermedia) de aquellos títulos a que se refiere la información, abarcando también otros actos jurídicos a ello dirigido. ${ }^{29}$

Así las cosas, las acciones típicas son las de suministrar la información a un tercero, por si o por intermedio de otra persona, o directamente utilizarla en su provecho. Ese abuso de la información privilegiada debe tener como finalidad la negociación, cotización, compra, venta o liquidación de valores negociables.

La idea esencial es la información privilegiada a la que el sujeto hubiera tenido acceso en ocasión de su actividad, para la negociación, cotización, compra, venta o liquidación de valores negociables. La ley ha utilizado el termino correcto, el de que se trata de una información privilegiada, en el sentido de que algunos pocos la tienen. ${ }^{30}$

Por suministrar, se entiende proporcionar o poner al alcance de una persona o cosa algo que necesita aprovisionar, surtir, abastecer, facilitar, conceder, deparar, proporcionar, proveer. En otras palabras, quiere decir que la persona revela o entrega dicha información a una tercera persona.

Por utilizar se entiende aprovecharse o servirse de algo o alguien. En este caso es aprovecharse de esta información a los fines de obtener una mayor rentabilidad, por sobre la que obtendrán los demás. Como los autores tienen la obligación de reservar esos datos, lo que expresamente se castiga es el suministrar o utilizarlos.

Para Donna sin perjuicio de que resulte dable inferir que las acciones incriminadas podrían tener en el aspecto subjetivo del tipo una ultrafinalidad como es la de obtener un rédito económico, lo cierto es que ello no surge de la norma por lo que, a fin de no vulnerar el principio de legalidad, solo se requiere que el autor las cometa para "la negociación, cotización, compre, venta o liquidación de valores negociables". Y este punto es más que importante para catalogar a estos tipos penales. ${ }^{31}$

28 ORCE, Guillermo: Código Penal y normas complementarias. Análisis doctrina y jurisprudencia. Tomo. 12, parte especial. Buenos Aires, Edit. Hammurabi, 2013. p. 626

29 FOFFANI, op. cit., p. 115.

30 DONNA, op. cit., p.534

31 DONNA, op. cit., p.535 
Según Dörte Poelzig, la información tiene que ser precisa, es "precisa" (en el sentido del $\S 7$, apartado 1, del MAR) si es lo suficientemente específica como para permitir que se extraiga una conclusión sobre los posibles efectos de las circunstancias o del acontecimiento en el precio de los instrumentos financieros. La característica de la especificidad del precio filtra la información obviamente irrelevante, de modo que se puede prescindir de un examen exhaustivo de la relevancia del precio. ${ }^{32}$

Según el §7, párr. 2, del MAR alemana, la información sobre circunstancias o acontecimientos futuros también puede ser precisa incluso antes de que se produzcan, tan pronto como pueda esperarse razonablemente que existan o se produzcan. Para ello, hay que tener en cuenta la perspectiva del inversor razonable. La cuestión es si el inversor razonable, teniendo en cuenta todos los indicios disponibles, espera que se produzca esa circunstancia. Lo que se requiere es una probabilidad realista. $^{33}$

Según la jurisprudencia del EuGH ${ }^{34}$ en el caso "Lafonta", no es necesario para la especificidad del precio que la información permita predecir la dirección del movimiento del precio. Para clasificar la información como precisa, basta con que la información tenga un impacto en el precio de las acciones cuando se conozca, aunque no esté claro si el mercado valorará el proyecto positiva o negativamente. La información que no es precisa incluye, en particular, conjeturas o especulaciones meramente vagas. ${ }^{35}$

Señala Tiedemann que, cumplen con la exigencia de información privilegiada, los datos económicos empresariales tales como el volumen de negocios, el de beneficios, pero también las ofertas de fusiones y la información de mercado relativa a la empresa. ${ }^{36}$

Pongamos un caso real de acciones y veamos que hubiera pasado si se hubiera utilizado dicha información de tal manera que se diera el tipo penal del art. 307 del CP.

En 1990 Capital Cities/ABC, debido a una recesión económica, los ingresos por publicidad empezaron a descender, y Capital Cities informo que sus beneficios netos en 1990 serian casi idénticos a los de 1989. La bolsa, acostumbrada a un crecimiento de los beneficios de Capital Cities

32 POELZIG, op. cit., p. $177, \mathrm{n}^{\circ} .372$

33 POELZIG op. cit., p.177/8. nº 373

34 Europäischer Gerichtshof

35 Ibídem

36 TIEDEMANN, op. cit., p. 385. 
de cerca del $27 \%$ al año reacciono violentamente y en tan solo seis meses redujo el precio de las acciones de 69,3 dólares la acción a 38 dólares la acción. Así Capital Cities perdió el $40 \%$ del precio de sus acciones, y todo porque sus previsiones eran mantenerse igual que el año anterior. Ahora bien, en 1995 Capital Cities y The Walt Disney Company acordaron fusionarse. Esto hizo subir las acciones de Capital Cities hasta 125 dólares la acción. Comprando una acción en 1990 a 38 dólares y vendiéndola en 1995 a 125, la tasa de rentabilidad compuesta anual antes del impuesto que se obtenía era del $26 \%$, con uno beneficios de 87 dólares. $^{37}$

La información anticipada de que iba a ocurrir la fusión entre las dos empresas, es información privilegiada, hasta tanto no se haga publica dicha maniobra. Si algunos de los directivos que participaban de estas negociaciones o un empleado que se enterara hubieran comprado o mandando a un tercero a comprar acciones de Capital Cities estarían incurriendo en el tipo penal. Sabiendo de la fusión, especulando que las acciones subirían, hubieran comprado acciones por un valor de 38 dólares y luego de la fusión las hubieran vendido a 125 y eso hubiera sido utilizar información privilegiada. Distinto sería el caso si una vez que se hiciera publica la decisión hubieran salido a comprar acciones, toda vez que la información ya era conocida por todos y todos estaban en igualdad de posiciones (aunque puede ser discutido también).

\section{Objeto.}

Desde un punto de vista objetivo, la conducta consiste en la adquisición, transmisión o cesión de un instrumento financiero, o en la cancelación o modificación de una orden relativa a este tipo de objeto, usando información privilegiada a la que se ha tenido acceso reservado. También se castiga, la conducta de recomendar a un tercero el uso de información privilegiada para llevar a cabo tales operaciones. ${ }^{38}$

De esta manera, se trata de toda información reservada de cualquier clase de valores o instrumentos negociables en algún mercado organizado oficia o reconocido a la que haya tenido acceso el autor del hecho. Información

37 BUFFET, Mary - CLARK, David: Buffettologia. Paidos Bs.As. 2021. p152-53

38 ESTRADA I CUADRAS, Albert: "Delito de abuso de información privilegiada (insider trading)". En: Lecciones de derecho penal económico y de la empresa. Silva Sánchez Jesús María (dir), Edit. Atelier. Barcelona 2020. p. 517 
que debía quedar secreta y que el sujeto la conoce por su actividad interna y que, en el momento del hecho, no ha trascendido al exterior. ${ }^{39}$

En el artículo 7 del decreto 677/01 establece la obligación de guardar reserva para una amplia gama de sujetos con acceso a información reservada o privilegiada en el ámbito de la oferta pública. Adicionalmente, el artículo 33 del mismo cuerpo normativo reitera el carácter ilícito de la conducta, al proveer las acciones de recupero contra quienes, violando dicha prohibición, hubieren obtenido, para sí o para terceros, ventajas de cualquier tipo. ${ }^{40}$

Por su parte, las Normas de la Comisión Nacional de Valores, (libro 6, Transparencia, capitulo XXI) reglamentan la obligación de guardar reserva de la información relevante sin divulgación publica (artículo 15), enunciando las conductas expresamente prohibidas (artículo 27). ${ }^{41}$

La parte final del artículo 307 del CP, conecta con la segunda acción típica (utilizar) se refiera a la "negociación cotización, compra, venta o liquidación de valores negociables. ${ }^{42}$ El artículo 2 del decreto 677/01 se refiere a que se entiende por valores negociables.

En Alemania, el $\S 14$ de MAR prohíbe (1) las operaciones con información privilegiada, es decir, el uso de información privilegiada para adquirir o ceder instrumentos financieros ( $\$ 8$ párr. 1; 14 letra a de MAR); (2) la recomendación o instigación para adquirir o ceder instrumentos financieros sobre la base de información privilegiada, así como el uso de recomendaciones o instigaciones ( $\$ 8$ párr. 2,3; 14 letra b MAR y, por último, (3) la divulgación ilícita de información privilegiada ( $\$ 8$ párr. 3, 14 letra c de MAR). De conformidad con el §7 (1) (a) del MAR, la información precisa debe referirse a uno o más emisores o a los propios instrumentos financieros de conformidad con el artículo 7 (1) (a) de MAR.

Por ejemplo, la información relativa a los instrumentos financieros son, las ofertas públicas de adquisición de otra empresa, la situación de los pedidos en la bolsa de valores o las medidas de mantenimiento de precios. ${ }^{43}$

La información con referencia al emisor puede ser tanto de procesos internos como de circunstancias externas. Por ejemplo, la información

39 DONNA, op. cit., p.536

40 PAOLANTONIO ,Martin E.: Derecho penal y Mercado Financiero: ley 26.733. Edit. Abeledo-Perrot. Bs.As. 2012. p.64

41 PAOLANTONIO. op. cit., p. 66

42 PAOLANTONIO, op. cit., p.105

43 POELZIG, op. cit., p. 182 
interna con referencia al emisor es, por ejemplo, las cifras trimestrales, los informes de beneficios o las decisiones de personal. Si otra empresa hace un pedido importante al emisor, o lo demanda, o si se produce una decisión judicial positiva o negativa para el emisor, entonces hay información relacionada con el emisor externa a la empresa. ${ }^{44}$

Otro ejemplo puede ser, la información privilegiada indirecta que, en principio, (puede cumplir los criterios del §7, apartado 1, a) de MAR) son, por ejemplo, las decisiones sobre los tipos de interés clave de los bancos centrales o los cambios en los precios de las materias primas en el sector del emisor. ${ }^{45}$

\section{Autor.}

Es un delito especial propio ya que solo puede ser cometido por los directores, miembros de órganos de fiscalización, accionistas, representante de accionistas y todo el que por su trato, profesión o función dentro de una sociedad utilizare la información privilegiada.

O sea quien se deba obligación de silencio, de modo que solo será punible el insider y no así el outsider. Esto es, el deber se concreta en salvaguardar la información privilegiada. ${ }^{46}$

También será sujeto activo el que realice alguna de las acciones típicas estudiadas a través de una persona interpuesta. Esta última, resultando un extraneus, por carecer de las cualidades que exige la norma al autor, deberá responder a título de partícipe. ${ }^{47}$

Orce, entiende en este punto que el director siempre tendrá una información privilegiada respecto de tenedores comunes de valores de la empresa. Si no se limita el ámbito del tipo a través de alguna noción de daño (como lo hacen las agravantes del artículo 308) podría caerse en el absurdo de que toda negociación o incluso omisión de ella estuviera comprendida en el tipo. ${ }^{48}$

En efecto un director tiene información privilegiada si es que objetivamente se espera que la empresa tendrá ganancias (por ejemplo, se descubre un nuevo yacimiento) o perdidas (se fracasa en un proyecto

$44 \quad$ POELZIG, op. cit., p. 182

45 Ibídem

46 López Barja De Quiroga, cita en DONNA, op. cit. p. 537

47 DONNA, op. cit. p 537

48 ORCE, op. cit., p 633 
productivo o de prospección). Pero también tiene información privilegiada cuando se sabe que las cosas marcharan, según todas las previsiones, sin mayores cambios. Respecto del extraño que posee acciones y que no sabe si su precio bajara o subirá, el saber que las cosas seguirán igual es tener información privilegiada. En ese contexto la compra de acciones por parte de un director seria punible. Un absurdo que deriva de la forma de tipificación. ${ }^{49}$

Para Vásquez Palma, el asunto es que el cargo desempeñado le imprime no solo derechos, sino también deberes, y entre éstos se encuentran los de no utilizar la información privilegiada de ninguna de las formas establecidas en la LMV. Señalar que con ello se restringe sus derechos de propiedad y libertad económica es un fundamento feble, en tanto lo que se prohíbe es que estos sujetos no puedan utilizar la información "mientras tenga el carácter de privilegiada", tomando en consideración que en principio se trata de un período breve (de horas), para no provocar distorsiones en la operatividad del mercado de valores y discriminaciones injustificadas. Una vez que la información deja de tener tal carácter, el sujeto puede hacer las operaciones que estime pertinentes. ${ }^{50}$

En el actual artículo 285 del CP español, contiene dos tipos penales, uno de especial, que solo pueden cometerlo aquellos que hayan tenido acceso reservado a la información privilegiada (insider primarios - 285.1 CP), $\mathrm{y}$ otro de común, que puede cometer cualquier persona que haya tenido acceso a la información, por cualquier medio (insider secundario), y sepa que es información privilegiada (artículo $285.5 \mathrm{CP}){ }^{51}$

Por ejemplo, realiza el comportamiento típico, el abogado que presta sus servicios en un gran bufete de abogados, se entera del inminente lanzamiento de una oferta de adquisición de una empresa sobre otra preparada por un compañero y, en vista de ello, adquieren acciones la sociedad que va a ser adquirida. Este es el denominado caso del siglo de la Coste de los EEUU con un beneficio del abogado O'Hagan de alrededor de 4,3 millones de dólares..$^{52}$

En la SAP-Madrid 556/2017, (ponente García Quesada), se condena por este delito al miembro del consejo de administración de una empresa

49 Ibídem

50 VÁSQUEZ PALMA, op. cit., pp 416-484.

51 ESTRADA I CUADRAS, op. cit., p. 549

52 TIEDEMANN, Klaus: Manual de Derecho penal económico. Parte general y Especial. Edit. Tirant Lo Blanch. p. 384. 
hotelera que dimitió de su cargo y vendió una parte de sus acciones (la necesaria para tener un porcentaje inferior al $5 \%$ del capital) poco antes de realizar operaciones masivas de ventas de acciones de la empresa con base a información privilegiada (el precio al que otras empresas estaban dispuestas a pagar la acción para realizar una OPA) que había conocido por razón de su cargo. ${ }^{53}$

\section{Tipo subjetivo.}

Solo admite dolo directo. Toda vez que, se requiere que el autor suministre o utilice la información privilegiada a la que hubiera tenido acceso en ocasión de su actividad y además que ella sirva para la negociación, cotización, compra, venta o liquidación de valores negociables. En consecuencia debe saber el carácter de la información y su voluntad de darla a terceros. No se admite el tipo imprudente. ${ }^{54}$

Señala María Fernanda Vásquez Palma que, debe comprenderse que lo que se requiere es de un elemento volitivo de parte del sujeto, toda vez que el legislador impide su utilización "en beneficio" propio o ajeno, o valerse de la información "para" obtener beneficios o evitar pérdidas. En tal sentido, todo uso de información privilegiada conlleva una idea de ganancia o asume la idea de beneficio, es parte de su esencia, en tanto el sujeto sabe que por medio de su uso está en una posición de ventaja comparativa con el resto de los inversores. Una cuestión distinta es que ello, en definitiva, no suceda. De manera tal, que no es algo que deba acreditarse, solo bastará con probar tal actuar. ${ }^{55}$

\section{Consumación y tentativa.}

Al tratarse de un delito de deber, el delito se consuma con el mero incumplimiento del deber, por lo menos en este tipo penal. Esto es, el suministro o la utilización de la información privilegiada, sin necesidad de beneficios económicos para el autor o terceros. ${ }^{56}$

Para Foffani, el insider trading se configura como un delito de mera actividad. Si bien se trata de una conducta con la que el insider intenta

\footnotetext{
53 ESTRADA I CUADRAS, op. cit., p. 550

54 DONNA, op. cit., p 536.

55 VÁSQUEZ PALMA, op. cit., pp 416-484.

56 DONNA, op. cit., p 537
} 
obtener un beneficio, el beneficio económico (del mismo modo que el perjuicio económico) no forma parte del tipo. ${ }^{57}$

La prohibición de divulgación en virtud del $\S 14 n^{\circ} 2$ de la WpHG alemana, tiene por objeto prevenir el peligro de las operaciones con información privilegiada de antemano. De esta manera, la divulgación puede hacerse de forma activa, comunicando la información privilegiada a un tercero, o de forma pasiva, haciéndola accesible. Por lo tanto, para la segunda alternativa, bastaría con que el tercero fuera puesto por la persona con información privilegiada en situación de obtener la información privilegiada por sí mismo, por ejemplo, mediante la entrega de una contraseña de la computadora o teléfono. ${ }^{58}$

En el $\$ 10$ (1) MAR alemana, la divulgación es generalmente ilegal a menos que se haga en el curso normal del empleo, la profesión o las funciones. La ilegalidad es un elemento constitutivo y no una mera referencia al requisito general de la ilegalidad. La doctrina dominante consideraba inicialmente lícita cualquier revelación requerida por razones operativas sobre la base de la antigua versión de la MAR, siempre que estuviera dentro del ámbito normal del ejercicio de la profesión y del negocio. En cualquier caso, la divulgación de información dentro de una empresa o a personas obligadas a guardar el secreto profesional, como los abogados en particular, debe considerarse regularmente como autorizada, siempre que la información sirva de algún modo para el desempeño de tareas operativas. ${ }^{59} \mathrm{La}$ información privilegiada debe ser idónea para influir considerablemente en la cotización una vez que haya sido conocida públicamente, y debe tratarse de una información precisa, de manera que no basta los simples rumores de la Bolsa. ${ }^{60}$

Sin embargo, el EuGH aplicó normas más estrictas en su decisión sobre Grongaad \& Bang- Entscheidung. Dado que la divulgación legítima debe interpretarse de forma restrictiva como una excepción a la prohibición de divulgación aplicable de forma general, la divulgación debe ser indispensable para el desempeño de un trabajo o el cumplimiento de una tarea y debe cumplir el principio de proporcionalidad. Por lo tanto, es necesario sopesar la finalidad de la prohibición de divulgación y el interés de la persona con información privilegiada en la divulgación. Sobre todo,

57 FOFFANI, op. cit., p. 115.

58 POELZIG, op. cit., p. 198.

59 POELZIG, op. cit., p. 199.

60 TIEDEMANN, op. cit., p. 385. 
debe tenerse en cuenta la sensibilidad al precio de la respectiva información privilegiada, de modo que deben establecerse requisitos estrictos sobre la licitud de su divulgación para circunstancias extraordinariamente relevantes para el precio. ${ }^{61}$

Esta jurisprudencia también se aplica al $§ 10$, apartado 1, parr.1, s. 2 MAR. La redacción no prevé tal restricción. Sin embargo, la disposición se corresponde con el $\$ 3$ MAD o la Directiva sobre operaciones con información privilegiada, en base a la cual se dictó la sentencia Grongaad \& Bang-Entscheidung del Tribunal de Justicia de las Comunidades Europeas. La divulgación también puede ser necesaria por razones legales, en particular. ${ }^{62}$

\section{Pasos intermedios como información privilegiada.}

Los pasos intermedios, que pueden ser información precisa según el $\S 7$ párrafo 2 MAR, también deben ser relevantes para el precio con el fin de constituir información privilegiada (véase el $\S 7$ párr. 3 de MAR). Según el Tribunal Federal de Justicia alemán y la opinión mayoritaria que le sigue, un paso intermedio puede ser en sí mismo sensible al precio. Sin embargo, la relevancia del precio de un paso intermedio suele derivarse de la relevancia del precio de un posible anuncio de evento final. Pero, se discute con qué probabilidad debe esperarse la ocurrencia de este evento final para que el paso intermedio sea relevante para el precio. ${ }^{63}$

Por lo tanto, en este punto debe aplicarse la prueba de probabilidadmagnitud, ya que un inversor razonable también tendrá en cuenta los efectos del evento final en su decisión de inversión, además de la probabilidad de que se produzca. Cuanto más significativo sea el suceso final, menores pueden ser los requisitos de probabilidad de ocurrencia. Ahora bien, el enfoque de probabilidad-magnitud fue rechazado expresamente por el EuGH ${ }^{64}$ para la clasificación de las circunstancias futuras como información precisa de acuerdo con el $\S 7$ (2) del MAR, ya que de otro modo se mezclarían los elementos constitutivos de la especificidad del precio y la relevancia del mismo. ${ }^{65}$

\footnotetext{
61 POELZIG, op. cit., p. 200.

62 Ibidem

63 POELZIG, op. cit., p. 186/7 n³87

64 Eropäischer Gerichtshof

65 POELZIG, op. cit., p. 186/7
} 
Sin embargo, señala Poelzig que, esto no se aplica al problema en cuestión, ya que la relevancia del precio de un paso intermedio sólo se justifica por la relevancia del precio del evento final y, por lo tanto, no se mezclan los elementos del delito entre sí. Se discute si la fórmula de probabilidad-magnitud debe completarse con el requisito de una probabilidad mínima inferior al 50\%. El argumento a favor de esto es que, de lo contrario, la presunción de información privilegiada -especialmente en el caso de acontecimientos finales especialmente graves- se adelantaría demasiado. ${ }^{66}$

\section{Agravante.}

El artículo 307 debe leerse concomitantemente con las agravantes previstas en el artículo 308 en sus incs b) y c). Mientras que en estos últimos supuestos se requiere una suerte de resultado que, por cierto, es ambivalente en los dos incisos, el tipo del artículo 307 parece prohibir el mero uso de a información privilegiada aun cuando esta no ocasione daño a terceros ni implique un beneficio para el autor. ${ }^{67}$

Así, la norma prevé dos grupos de agravantes:

Se incrementa la pena de tipo básico de dos a seis años de prisión cuando:

Exista habitualidad, en este punto lo determinante es la repetición del mismo tipo de conducta por parte del autor. Para ello bastaría que el sujeto lo haya realizado dos veces, para que jugara el agravante. Según Donna, esta no es la idea de la norma, sino que exista una especie de forma de actuar, consiste en que reiteradamente se dedique a realizar este tipo penal de conductas, de modo que no es el número, que debe existir, sino la forma en que realiza esta actividad. ${ }^{68}$ Se logare un beneficio o se evitare un perjuicio, en este caso la figura se agrava al concurrir una circunstancia objetiva, el beneficio económico o evitar el perjuicio de este tipo.

En otras palabras, si el autor además de violentar un deber, en estos ámbitos de absoluta confianza, se beneficia económicamente, o evita un perjuicio de esa índole, tanto para el como para terceros, es lógico que la sanción se aumente. En estos casos, un dato que no se debería hacer público

\footnotetext{
66 Ibidem

67 ORCE. op. cit., p 631

68 DONNA, op. cit., p 538
} 
pueda dar ganancias extraordinarias, en principio de la igualdad de quienes participan en este mercado. ${ }^{69}$

$\underline{\text { Se incrementa el máximo de la escala agravada a la pena de } 8 \text { años de }}$ prisión

Se causare un grave perjuicio en el mercado de valores, se entiende que dicho perjuicio debe ser económico, sino se estaría repitiendo el tipo básico. En estos casos se puede ocasionar la quiebra de empresas, junto con el costo social que ello conlleva. ${ }^{70}$

El perjuicio debe tener relación directa con el deber incumplido, cualquier otro daño, lejos de este deber, no será alcanzado por las agravantes.

Por la especial calidad del autor, la pena se incrementa cuando el abuso de información privilegiada proviene de un miembro importancia en el escalafón (gerente, director) o de un empleado de una entidad autorregulada -que comprende a las bolsas de comercio y los mercados de valores, llamados entidades autorreguladas bursátiles y el mercado abierto electrónico (MAE), denominado entidad autorregulada extrabursátil- o de una sociedad calificadora de riesgos- o sea las sociedades anónimas normales formadas por especialistas que dan un opinión técnica independientemente de la capacidad de repago en tiempo $\mathrm{y}$ forma de los distintos negociables (obligaciones negociables y/u otros títulos de deuda) o bien, el autor se trate de un sujeto cuya profesión requiera habilitación o matricula). ${ }^{71}$

\section{CONCLUSIONES.}

Como se ha expuesto al comienzo de este trabajo, el precio en el mercado de valores resulta de suma importancia, mas allá del sistema que se adopte a los fines de invertir, la idea de que el precio lo descuenta todo, también implica ver en el precio la información necesaria a los fines de poder comprar o vender y a partir de allí realizar un análisis acabado de corto, mediano y largo plazo.

Las personas son racionales y buscaran maximizar sus beneficios, y en esa búsqueda pueden desviar el rumbo a lo delictivo. Ese acto conlleva

\footnotetext{
69 Ibídem

70 DONNA, op. cit., p 539

71 ibídem
} 
costos sociales altos, ya que afecta el capital social, por ende, vulnera el sistema de cooperación social y esto taca a la autonomía de la persona. ${ }^{72}$

De esta manera el tipo penal resulta importante a los fines de poder garantizar en el inversor chico, mediano o grande un análisis medianamente y un plan de inversión basado en las predicciones del análisis dentro de la incertidumbre que puede representar el mercado.

Esto no quiere decir que el Estado está regulando la oferta-demanda de papeles, lo que está haciendo es volviendo el mercado apto para que la oferta y la demanda puedan funcionar en el libre mercado. Justamente quienes realizan el tipo penal del art. 307 están contra el libre mercado, dado que no permiten que este se mueva mediante la oferta- demanda, lo que hacen es aprovecharse de este, convirtiéndose en free rider, generando una externalidad negativa que implica un costo alto para el sistema, por una parte, el coste implica que se pierda credibilidad en el mercado y por el otro en la norma.

De esta manera el tipo penal está asegurando la libre competencia en el mercado. Para ello, la sanción penal cumple una función importante, de esta manera lo que se está utilizando es la prevención general negativa en su versión actualizada. Quienes actúan en este mercado son personas que realizaran un análisis costo-beneficio a los fines de evaluar si les conviene o no detractar con la norma, ${ }^{73}$ esto se debe a que son sujetos que tienen una formación especializada en el tema.

La información necesaria para la especificidad del precio es que, esta permita predecir la dirección del movimiento del precio. Para clasificar la información como precisa, basta con que tenga un impacto en el precio de las acciones cuando se conozca. La información que no es precisa incluye, conjeturas o especulaciones meramente vagas.

72 DONNA, Sebastian A.: Las teorías de la pena. Un análisis jurídico-económico. Rubilzal-Culzoni. 2021. p.290

73 DONNA, Sebastian Alberto: Las teorías de la pena, un análisis Jurídico - Económico. Rubinzal-Culzoni. 2021; "La pena como desincentivo al incentivo negativo que genera el seguro de depósito y el "too big to fail" en el sistema bancario". En: Revista de Derecho Penal, Derecho Penal Económico 2020-2. Derecho bancario, Cambiario y Financiero. Relación con el Derecho Penal - II, Edit. Rubinzal-Culzoni. 2021; "El $\S 54^{\mathrm{a}}$ de la Ley de créditos. Ley bancaria- KWG alemana (Gesetz über das Kreditwesen. Kreditwesengesetz) y la prevención general negativa”. En: Revista de Derecho penal económico. 2020-1 Derecho Bancario, Cambiario y financiero. Relación con el Derecho penal-I. Edit. Rubinzal-Culzoni. 2020. 
La información privilegiada, afecta al precio de los papeles, ello se debe a que mediante la información se está aprovechando del precio, por ejemplo, la persona que sabe que dos bancos medianos se fusionarán, implicara que sus acciones suban, pero además también entraría en la categoría too big to fail, ello daría más garantías a los inversores que el Estado lo salvaría ante cualquier consecuencia.

Quien tenga esa información en principio comprará las acciones a un precio mas barato, y si la fusión se lleva a cabo el precio de estas aumentará brindando un mayor rendimiento de las mismas. Acá viene el problema, es posible que, mediante esa compra de papeles, haga subir el precio de la misma (dado el volumen de compra), esto implicaría que personas compren mas caro esos papeles, que de otra forma hubieran pagado otro precio o tal vez nunca los hubieran comprado. O si todos hubieran tenido esa información hubieran comprado a un precio mas barato, o a la inversa quizás no comprar para que el precio no suba.

Como es sabido, en la bolsa cuanto más personas compran un papel el precio de este irá en aumento, como todos lo quieren se venderá cada vez mas caro (es a la inversa de la teoría económica de la oferta-demanda en cuanto a mayor demanda hace bajar el valor de la mercancía) hasta llegar al punto de equilibrio, luego el ciclo lleva a que mas que un precio $\mathrm{X}$ no estén dispuestos a pagar, a partir de allí, en principio, si esta sobre vendido el papel el precio bajará. ${ }^{74}$

Lo mismo ocurriría si nos pasan la información que una empresa o banco se declara en banca rota, y vendemos las acciones antes de que se conozca la noticia. Otro ejemplo, sabemos que por una inversión las acciones de una empresa subirán, y se busca dar una información falsa al mercado para que el precio caiga, así compramos mas barato y cuando la empresa haga la inversión y se dispare el precio de esta manera nuestros papeles incrementaran el valor.

Un ejemplo concreto de como se deben hacer las cosas, ocurrió con el papel de LOMA (Argentina), había tenido una caida del precio y parecia que no iba a romper la resistencia, hasta que la empresa anunció públicamente la recompra de acciones, al otro día empezo a subir el precio, distinto hubiera sido si un directivo de la empresa con esa información hubiera salido a comprar miles de acciones de LOMA a un precio bajo

74 Lo que se conoce como la puja entre alcistas y bajistas. Los compradores no están dispuestos a pagar se precio y los vendedores a vender a ese precio y allí comienza esa puja para ver quien gana. 
para luego cuando suban revenderlas, esto último es lo que sanciona el tipo penal. Otro ejemplo, que se puede utilizar fue el de la inmobiliaria china Evergrande cuando se dio la noticia que estaba en quiebra todo los mercados cayeron (EEUU y EU), si alguien hubiera tenido esa informacion por adelantado podria haber vendido antes de que el precio cayera.

Ahora bien, de esta manera lo que se está protegiendo es el funcionamiento del mercado de capitales como sistema, esto quiere decir el sistema económico-financiero, en consecuencia, al hacerlo también se protege el patrimonio de los inversores, ya sean personas físicas o jurídicas.

En síntesis, quien evalúa sus costos y beneficios, en este mercado, verá si maximizará o no su renta, esto es lo que lo llevará a priorizar si cosificará o no a una persona para lograr sus fines personales. Así planteado sería un caso micro, pero elevado a la violación del Derecho pasa a ser un caso macro, lo que está realizando es una cosificación de la autonomía de la comunidad al atacar el capital social, de esta forma el delito violenta al derecho como moderador o regulador de la coordinación social. Esto lleva a pensar que lo que está en juego es el derecho y no el bien jurídico como tal. ${ }^{75}$

\section{BIBLIOGRAFÍA.}

ABOSO, Gustavo Eduardo. Código Penal. Comentado, concordado con jurisprudencia, 4 edición, BdeF, 2017

BASCUÑÁN, Antonio: "El estatus en el derecho chileno de las operaciones con valores realizadas en ejecución de una orden impartida antes de la posesión de información privilegiada y de su cancelación". En: Política crim. Vol. 12, No 24, diciembre 2017.

BASILICO, Ángel Ricardo y otros. Delitos contra el orden económico y financiero. Astrea; buenos Aires, 2019.

BUFFET, Mary - CLARK, David: Buffettologia. Paidos. Buenos Aires, 2021

75 DONNA, Sebastian A.: Las teorías de la pena, un análisis Jurídico - Económico. Rubinzal-Culzoni. 2021. p.292 
DONNA Edgardo A: Derecho penal. Parte especial. Tomo IV. 3 edición actualizada. Rubinzal-Culzoni. Santa Fe, 2014.

DONNA, Sebastian A.: Las teorías de la pena, un análisis Jurídico Económico, Rubinzal-Culzoni, Santa Fe, 2021

-"El §54 de la Ley de créditos. Ley bancaria- KWG alemana (Gesetz über das Kreditwesen. Kreditwesengesetz) y la prevención general negativa": En: Revista de Derecho penal económico. 2020-1. Derecho Bancario, Cambiario y financiero. Relación con el Derecho penal-I. Edit. RubinzalCulzoni. 2020.

-"La pena como desincentivo al incentivo negativo que genera el seguro de deposito y el "too big to fail" en el sistema bancario". En: Revista de Derecho Penal, Derecho Penal Económico, 2020-2 Derecho bancario, Cambiario y Financiero. Relación con el Derecho Penal - II, Edit. Rubinzal-Culzoni. 2021.

EGGERTSSON, Thrainn: Economic behavior and institutions. Cambridge surveys of economic literature, UK, 2003

FRIEDMAN, Milton y Rose: Libertad de elegir. Biblioteca económica. Madrid. 1983

GARCIA PALOMINOS, Gonzalo: "Modelo de protección en normas administrativas y penales que regulan el abuso de Información Privilegiada en la legislación chilena”. En: Política crim., Vol. 8, No 15 (Julio 2013) [http://www.politicacriminal.cl/Vol_08/n_15/Vol8N15A2.pdf]

GUZMÁN, Nicolas: Delitos en el mercado financiero. Hammurabi. Buenos Aires, 2019

MEGGIOLARO, Ignacio Martín: Insider Trading en Argentina. La "no prohibición" como alternativa regulatoria. Tesis Maestría Derecho y Economía Universidad Torcuato Di Tella. Buenos Aires, 2015.

MOLTO, García Tomas: Material de economía política, $2^{\circ} \mathrm{ed}$, ampl. Arial, Barcelona, 2001

MURPHY, John J.: Análisis técnico de los mercados financieros. Planeta, Barcelona, 2018.

ORCE, Guillermo: Manipulación del precio de valores negociables u otros instrumentos financieros, en Código Penal y normas complementarias. 
Análisis doctrina y jurisprudencia. Tomo. 12. Hammurabi, Buenos Aires, 2013

PAOLANTONIO, Martin E.: Derecho penal y Mercado Financiero: ley 26.733. Abeledo-Perrot, Buenos Aires, 2012

POELZIG, Dörte: Kapitalmarktrecht. C.H. Beck, 2018

RIQUERT, Marcelo (dir): Insolvencias punibles y delitos contra el orden económico y financiero. Hammurabi, Buenos Aires, 2017

SAMUELSON, Paul \& NORDHAUS, William: Economía, con aplicaciones a Latinoamérica. 19a ed. McGraw Hill Educación, 2010

SILVA SÁNCHEZ, Jesús María (dir.), ROBLES PLANES, Ricardo (coord.): Lecciones de Derecho penal Económico y de la Empresa. Parte General y Especial. Atelier, Barcelona, 2020.

SOLA, Juan Vicente: Tratado de Derecho y Economía, t.1 Herramientas de Economía para el análisis jurídico. La Ley, 2013.

TAPIA, Gustavo (coordinador): MERCADO DE CAPITALES. INTERPRETACIÓN Y ACTUACIÓN. Omicrom System, CABA, 2013

THIESS, Peterson: Makroökonomie. Schritt für Schritt. 3 Auflage. Utb TIEDEMANN, Klaus (dir.), ADAN NIETO, Martin (coord.): Eurodelitos. El Derecho penal económico en la Unión Europea, Ediciones Universidad de Castilla-La Mancha, 2004

TIEDEMANN, Klaus: Manual de Derecho penal económico. Parte general y especial. Tirant Lo Blanch, Valencia 2010.

VÁSQUEZ PALMA, María Fernanda: "Caso LAN y uso de información privilegiada: un análisis de la correcta delimitación de las infracciones legales." En: Revista Ius Praxis, Año 16 n² 2010.

VEGA GUTIÉRREZ, José Zamyr: Mercado de Valores en Derecho penal. Abuso de información privilegiada bursátil: Insider Trading. BdeF., Madrid, 2013

WEINSTEIN, Stan: Secretos para ganar en los mercados alcistas y bajistas. Valor Ediciones, Barcelona 2014.

ZUNZUNEGUI, Fernando: ¿Qué es el insider trading? En: Revista de Derecho del Mercado Financiero. rdmf.wordpress.com. Octubre de 2006. 